\title{
A Study into Solutions to Negative Environmental Externalities of Rural Tourism*
}

\author{
Yingying Zeng, Zining Jin \\ School of Environment and Energy, Peking University, Shenzhen, China \\ Christine.Zeng14@gmail.com, ziningjin@gmail.com
}

\begin{abstract}
The negative environmental externalities caused by rural tourism has not only seriously damaged the local environment, but has also hindered the sustainable development of local tourism. In this paper, we analyze the two major obstacles when internalizing externalities of rural tourism with conventional solutions: difficulties in overcoming the information inadequacy and providing benefit compensation. In order to eliminate the adverse effects of externalities, a new idea is proposed that Rural Tourism Interest Community may have some advantages in tackling the above problems and internalizing negative externalities. At last, a case study of Tianlongtunbao Cultural Village is provided to demonstrate its advantages.
\end{abstract}

Index Terms - Rural tourism ; Negative Environmental Externalities ; Information inadequacy ; Benefit Compensation ; Interest Community

\section{Negative Environmental Externalities of Rural Tourism}

In recent years, rural tourism is booming everywhere. As an emerging industry, rural tourism has not only increased income but also brought about a series of increasingly prominent negative environmental externalities:

On the one hand, rural tourism negatively affects rural natural resources and ecological environment. In order to get more investment, local government's poor environmental management and law enforcement results in intrusive tourism development caused by tourism companies_- extensive damage not only to non-renewable resources but also to some well-known scenic areas, including serious soil and water loss deforestation and so on [1].

On the other hand, rural tourism negatively affects the rural social environment, causing inevitable destruction to local people's producing and living customs, cultural customs and historic sites [2]. Villagers become the main bearer of rural tourism negative externalities. For instance, in pursuit of maximizing profit local culture loses the essence of local indigenous culture and characteristics due to too much commercial packaging and blindly simulating, and thus seems superficial, which impedes local culture's development and inheritance [3].

Negative externalities on the ecological environment and social environment caused by the rural tourism have not only seriously threatened the sustainable development of rural tourism, but also severely disturbed the local social order, affecting the daily life of the villagers and harmony of rural area $[4,5]$.

\footnotetext{
* Supported by Shenzhen social science fund 125A071.
}

In spite of much study on rural environmental issues and tourism negative externalities, there is very little research on the negative externality of the rural tourism. Based on existed and disperse study, this article first proposed the two major obstacles of rural tourism negative externality internalization, then analyzed the two limitations of conventional solutions (Pigovian tax and the Coase property approach), and finally put forward a new solution named rural tourism interests community.

\section{II . Limitations of Conventional Solutions}

A. Two Major Obstacles of Rural Tourism Negative Externality Internalization

The root cause of negative externalities is the deviation of the Marginal Private Cost and Marginal Social Cost [6,7]. In order to solve the problem, negative externalities should be internalized — increasing the marginal private cost of the negative externalities producers to the Marginal Social Cost.

There are two major obstacles when internalizing externalities of rural tourism: difficulty in overcoming information inadequacy and difficulty in providing effective interest compensation for the villagers.

\section{1) Information Inadequacy}

Some people are in an favorable position because they could obtain information others have no access to due to differently objective conditions or subjective capabilities. Therefore, information inadequacy always results in injustice or inefficiency [8].

In rural areas, information inadequacy occurs between villages, government and villagers or government and the tourism companies. When internalizing the negative externalities of rural tourism, various unfavorable factors such as villagers' literacy deficiency and government's limited resources have further aggravated the problem of information inadequacy. In order to internalize the negative externalities of rural tourism, information inadequacy must be solved, otherwise the government would not be able to obtain enough information for interest compensation, villagers would continue to suffer the damage caused by negative externality, and tourism companies could not operate as well due to environmental pollution .

\section{2) Difficulties of Benefit Compensation for the Villagers}

With the rapid development of rural tourism, villagers' 
interests have already been neglected: on one hand, villagers sell their land, offer their houses and sell their labor, but only gain little income from tourism; on the other hand, villagers, as the main bearer of rural tourism negative externalities, have to endure the exhaust gas, waste and noise pollution without getting any benefit compensation.

In order to reduce the damage to the villagers, benefit compensation must be made. However, in reality, there are numerous operation obstacles during the interest compensation: on one hand, tourism company, as the main producer of negative externalities, will not take the initiative to compensate victims; on the other hand, it is very difficult for the villagers to obtain sufficient benefit compensation by themselves, considering the information inadequacy or their limited capability and resources. In this case, government intervention is necessary -- the government should either require tourism companies to compensate the villagers, or use financial resources to do so. However, government intervention can not function well either due to government's limited resources and low capability of accessing information .

However, benefit compensation, if not provided, would not only impede social justice, adversely affect the stability of the local community, but also negatively affect the environment and rural tourism. What is more, only by providing fair benefit compensation to villagers can they play an important role in the tourism development and environmental conservation .

\section{B. Limitations of Conventional Solutions}

When internalizing the negative externalities of rural tourism, two solutions suggested by academe(Pigovian tax and Coase property approach) both have certain limitations [9].

\section{1) Limitations of the Pigovian Tax}

Government, according to British economist Ronald Pigou, should levy tax on the negative externality producers to increase polluters' private marginal cost, forcing them to limit its negative externalities producing behaviors and ultimately set the output level in the place where marginal social value equals the marginal social cost. In this way, efficient allocation of resources could be realized [10].

In recent years, sewage fee and environmental tax based on the theory of Pigovian tax become popular throughout the world. The popularity could be ascribed to two aspects: high operability and companies' autonomy [11]. However, as far as the problem with which this paper is concerned, Pigovian tax has its own shortcomings:

\subsection{Information Inadequacy}

In theory, the levy of Pigovian tax requires full information about corporations' private cost, private benefit and social cost, which could never be attained in reality. [11] Thus, in actual operation, Government determines the Pigovian tax according to the environmental impact of pollution. In this case, two requirements should be met: First, Government must have adequate information to ensure that the Government's assessment of the environmental impact is objective. Second, polluters must have adequate information to balance revenue and penalties, and then make rational choice whether to produce or how much to produce.

In rural areas, tourism companies and some villagers provide tourism service. The tourism company is the main producer of negative externalities, while villagers are both the producer and bearer of the negative externalities. When government levy Pigovian tax on tourism companies, the government could obtain companies' environmental pollution information, and enterprises could also stand high information cost. However, when government turns to the villagers to collect tax, the above two requirements are no longer met[12]: on one hand, the number of the villagers is very large, and study on the environmental impact mechanism of the villagers' behaviors is still immature, thus it is difficult to assess their act's environmental impact; on the other hand, it is also extremely difficult for villagers to overcome the information cost considering their very limited ability and resources. Therefore, in the field of rural environmental protection, it is not feasible to levy Pigovian tax on farmers, at least from the viewpoint of information cost.

\subsection{Difficulty in Providing Effective Benefit Compensation for the Villagers}

Although the implied meaning of the Pigovian tax is that tax paid by the negative externalities producers should be directly used to compensate the victims who suffered the negative externalities damage. However, under the existed financial system in China, compensation does not come directly from the Pigovian tax levied by the government but from the subsidies, which is often not enough and not on time.

In this case, the villagers can only consult with the polluters or appeal for their own "justice" to get the compensation. However, with limited ability and resources they could not obtain enough information to prove damage they suffered caused by pollution, not to mention gain fair compensation. In this case, most of the villagers would prefer to endure pollution (within certain limits)[13], rather than fight for the compensation.

\section{2) Limitations of the Coase Property Approach}

Coase property approach, i.e. Coase theorem, states that the externality could be tackled by privately negotiating and redefining public property rights ownership when transaction cost is low and the number of participants is small. When carrying out Coase property approach, if public property rights is given to victims, polluters have to provide compensation for the victims to persuade them to accept the pollution; if public property rights is given to polluters, victims should offer compensation to polluters in order to persuade polluters to voluntarily stop producing and polluting [8].

The concept of property rights has opened up new windows for understanding the phenomenon of externalities. However, when addressing the negative externalities of rural tourism, Coase property approach has significant limitations:

\subsection{Information Inadequacy}

Coase property approach could not work when information is not adequate, thus internalization of rural 
tourism negative externalities is impossible:

On the one hand, Coase property approach requires that property rights ownership must be clear, which is impossible when it comes to public resources. In order to define the property rights ownership, we should first clearly define property rights boundary. However, when dealing with the negative externalities of rural tourism, public resources system is like a "black box" and our understanding of public resources' property rights is very limited. [12]. What is more, in technical level we can never clearly define its boundary.

On the other hand, Coase property approach works only when the number of transactors is small. However, the rural environmental issues often involve many people who affect and who are affected. Furthermore, in rural areas polluters could be very far from the victims, which makes it difficult to establish connections [12]. In this case, the above factors increase the communication cost and impede necessary information transfer between "negotiators", thereby hampering the redefinition of property rights ownership and the internalization of negative externalities.

\subsection{Difficulty in Providing Effective Benefit Compensation for the Villagers}

Whether Coase property approach could provide villagers effective compensation depends on the results of public property ownership definition:

If public property rights is given to the government or companies without providing benefit compensation for villagers, villagers could not be compensated for the damage caused by rural tourism, and also lose their original rightsthey should offer compensation to polluters in order to persuade polluters voluntarily stop polluting-which is completely unfair for the villagers. What is more, villagers are often in a unfavorable position in negotiation due to possibilities of companies' "rent-seeking", government corruption and villagers' limited resources.

If public property rights is given to villagers, polluters should provide benefit compensation in order to persuade villagers to accept the pollution of tourism. Theoretically, in this case, the Coase property approach can provide villagers effective compensation. However, in practice, when villagers try to negotiate with polluters (mainly tourism companies) with limited information and low negotiation skill, compensation they could obtain is still very limited.

In a word, it is difficult to provide the villagers with effective benefit compensation with Coase property approach.

\section{Advantages of "Rural Tourism Interest Community"}

\section{A. Overview of the "Rural Tourism Interest Community"}

Based on the foregoing analysis, this paper came up with a new idea that the establishment of "rural tourism interest community"may solve the problem of rural tourism negative externalities.

\section{1) Definition}

"Rural Tourism Interest Community "is an interest community composed of stakeholders including government, tourism companies and villagers. Members of the community share the common goal of tourism company's profits and the sustainable development of rural tourism on the basis of benefit-sharing and risk sharing. Specifically, the government is responsible for planning and infrastructure construction, tourism company is responsible for the management of rural tourism and environmental protection, while the villagers offer services under the management and supervision of tourism companies. Finally, tourism company's profits would be allocated among government, tourism companies and the villagers based on effective negotiation and consensus.

\section{2) The Theoretical Basis}

Coase argued, if there are two companies respectively in the upstream and downstream of a river, company A is the producer of the negative externalities, and company $\mathrm{B}$ is its victim. In order to eliminate negative externality, a simple and feasible way is to merge these two companies [9]. "Interest dispersion" is prone to produce negative externalities due to independence of interests, individuals will inevitably ignore the external costs caused by personal behaviors for the sake of themselves, resulting in negative externalities to society.

In this case, the idea of "merger" could be used to form an interest community including all stakeholders (producers and victims of negative externalities), so that individuals who care about personal profits start to pursue the common interest. In this way, not only negative externalities caused by dispersed interests could be reduced, but also two obstacles when internalizing negative externalities (the information inadequacy and benefit compensation) could be conquered more effectively.

\section{3) The Operation Characteristics}

Specifically, "Rural Tourism Interest Community" has the following three characteristics:

"Rural Tourism Interest Community" abides by the principle of "benefits sharing, risk sharing", which is conducive to give full play to the enthusiasm of all parties and their respective advantages: on the one hand, members of the community share the common goal, carry out their duties, and finally distribute tourism company's profits after joint consultation among the government, tourism, and villagers ; on the other hand, once environmental accidents or other emergencies happen, members should deal with the problem by negotiating and shouldering the cost together.

Tourism company manages rural tourism and protects the environment. In this way, environmental negative externalities of tourism are internalized and problem of asymmetric information could also be tackled.

"Rural Tourism Interest Community" could provide effective compensation for the villagers: on the one hand, villagers provide tourism services under the management and supervision of tourism company and obtain the corresponding reward; on the other hand, the villagers sell tourism products and acquire all the profits, thereby effectively safeguarding the interests of the villagers. 


\section{B. Advantages of "Rural Tourism Interest Community"}

Tourism company plays a core role in rural tourism interest community: not only plans and manages rural tourism, but also plays a crucial role in the process of rural tourism negative externalities internalization.

\section{1) Advantage of Access to Adequate Information}

With the help of the government and the villagers, tourism companies can be more flexible to protect environment and overcome the information inadequacy, thereby improving the quality of rural environment:

On the one hand, most of the travel company's employees are local villagers and they understand each other because of villagers' long-term coexistence, which largely minimizes company's information cost [13]. On the other hand, tourism company supervises and manages the rural environment by recruiting some professionals. In this way, requirements of information management could be met and scientific tourism planning (e.g.scientifical tourist capacity control) could also be developed.

2) Effective Benefit Compensation for the Villagers Provided by Interest Community

"Rural Tourism Interest Community" provide villagers with effective interest compensation, thereby effectively compensate the villagers for the negative externality damage tourism caused increasing the tourism income of villagers.

Villagers, as staff of tourism company, are both producer and main bearer of negative externalities. Although the villagers' abilities are limited, they could still supervise the company's operation and urge the company to make favorable decisions for the villagers. Granted that sometimes the company's final decisions are adverse to villagers, the villagers can still get more effective compensation due to more opportunities and more information from the internal side.

In addition, villagers could gain income by working for the tourism company or participating in the festival held by the tourism company. What is more, villagers could also make profits by selling goods or providing other tourism services themselves.

\section{Case Study — Tianlongtunbao Cultural Village}

In 2001, Tianlongtunbao Cultural Rural Tourism Village was officially launched in Guizhou, China. This village created a new rural tourism development model called "Government + tourism company + Peasant Association" (i.e. "Dragon Model") [14]. And this case could verify that the foregoing advantages of the "community model":

\section{1) Advantage of Access to Adequate Information}

In Tianlongtunbao Cultural Village, the tourism company obtained the authorization from Pingba county government and recruited local villagers to provide tourism service. Also, tourism company is responsible for the the town's environmental protection. Judging from the implementation results of "Dragon Model", the tourism company's environmental management model can be more flexible and effective in obtaining access to all kinds of information:
On the one hand, almost all the employees of the company were villagers( accounting for $95.25 \%$ of the total number), which minimizes information cost for the company to get a full understanding of the local environmental capacity , sewage and other environmental information [14].

On the other hand, the tourism company established Sanitation Department, recruited some professionals to supervise and manage the rural environment, and invested a lot of money in renovating parts of the tourism facilities and afforesting[14]. The main street in the village become much cleaner compared with earlier.

\section{2) Effective Benefit Compensation for the Villagers Provided by Interest Community}

In Tianlongtunbao Cultural Village, villagers could participate in tourism in the following ways: (1) working in the tourism companies. (2) participating in the festival activities organized by the tourism company and getting paid by the company. (3) selling goods or other tourism services with the help of the local government. (4) participating in tourism development planning through the Peasant Association. (5) attending the Company's training classes [14].

Tourism development model of the Tianlongtunbao Cultural Village provides a variety of opportunities for the villagers to participate in tourism development and environmental protection, which not only boosts the development of tourism, but also improvs the environment quality and speeds up poverty alleviation in the whole village.

It is true that the success of the "Dragon Model" entails rich tourism resources, rural surplus labor force and strong government support. Moreover, whether this model can last depends largely on the tourism company's operation and a fair income distribution mechanism. However, the outstanding results achieved by the "Dragon Model" has still fully illustrated the feasibility and possibility that idea of "interests community "could solve the problem of negative externality.

\section{Conclusion}

In short, sustainable development of rural tourism and the rural environment protection call for the internalization of the negative environmental externalities of rural tourism. Traditional solutions both have difficulties in overcoming the information inadequacy and providing enough benefit compensation for villagers. New idea of establishing Interest Community can effectively overcome two major obstacles and internalize the negative externalities.

\section{References}

[1] Zhou Lingqiang, "Research on the Sustainable Development of Rural Tourism in China”, Ecological Geography, vol. 24, no. 4, pp. 572-576 , 2004.

[2] Zhang Yan, et al, "Utilizing Culture To Boost Sustainable Development of Rural Tourism”, Agricultural Economy, no. 12, pp. 70 71, 2008.

[3] Hu Pan, “A Study in Externalities of Chinese Ecological Tourism," Market Modernization, no. 488, pp. 258-259, 2006.

[4] Zhu Guangwei, "Environmental Protection in Tourism Exploration and Sustainable Economical Development in Rural Region," Research of Agricultural Modernization, vol.21, no. 5, pp. 287-290, 2000. 
[5] Zhang Lin, "Sustainable Development of Rural Tourism -- Perspective of Property Rights,” Commercial Research, no. 4, pp. 192-196, 2011.

[6] Ao Rongjuan , "Research on Internalization of Tourism Exploitation Externality , "Areal Research and Development, vol.22, no.2, pp.79-82, 2003.

[7] Su Juan, "Study in Externalities of Tourism Exploitation,” Guangxi Social Science, no. 6, pp. 53-56, .2005.

[8] Zhang Yuanpeng, “An Intermediate Couse in Microeconomics,” Beijing: Peking University Press, pp. 444-455, 468-476, 2007.

[9] N. Gregory Mankiw, "Principles of Economics," Beijing:China Machine Press, pp.212 228, 2005.

[10] Su Ziming, “An Analysis to Internalization of Environment,” China Market, no. 52, pp. 149-150, 2011.
[11] Cui Yuming, Chang Yunkun, “A Comparative Analysis of Methods of Externality Internalization ,’Research of Development, no. 3, pp. 40-43 2007. [12] Luo Hong, "Public Strategical Solution of Externalities Internalization and Coarse Theorem,” Modern Business Trade Industry, vol.19, no. 12, 2007.

[13] Fei Xiaotong, "Peasant Life in China," Shanghai:Shanghai Renmin Press, 2007.

[14] Li Lejing, Chen Zhiyong, "Multi-dimensional Values of Village Residents Participating in Tourism Development and Suggestions for Improvement -- A Case Study of Tianlongtunbao Cultural Village,” Tourism Tribune, no. 7, pp. 40-46, 2007. 